\title{
The Comparison of Metaheuristic Algorithms in Parametric Optimization of Laser-Based Processes
}

\author{
TATJANA V. ŠIBALIJA, Belgrade Metropolitan University, \\ Faculty of Information Technology; \\ Original scientific paper \\ Faculty of Management, Belgrade \\ UDC: $621.7 / .9] .048$ \\ 621.375 .826 \\ SANJA Z. PETRONIĆ, The Academy of Applied, \\ DOI: 10.5937/tehnika2102165S
}

Technical Studies Department of Belgrade Polytechnic, Belgrade

\begin{abstract}
The paper presents parametric optimization of two heterogeneous laser-based processes with multiple outputs (laser drilling and laser shock peening), using an advanced optimisation methodology. The data obtained from experimentations are processed by statistical method to address requirements for multiple responses, and then the process interrelationships are mapped using artificial neural networks. The neural process model is fed into three major metaheuristic algorithms whose effectiveness are benchmarked: genetic algorithm, simulated annealing and particle swarm optimization. The results are discussed in terms of the quality of the obtained solutions and convergence rate, as well as the influence of the algorithm's hyper-parameters on the obtained results. The adopted optimization results are successfully verified in practice. The recommendations for the metaheuristic algorithm selection and guidelines for the algorithm settings are drawn.
\end{abstract}

Key words: particle swarm optimization (PSO), simulated annealing (SA), genetic algorithm (GA), parametric optimization, laser drilling, laser shock peening (LSP)

\section{INTRODUCTION}

The use of lasers in material processing has become widespread in recent years and covers a variety of materials. The growing demand for zero tolerance of machine parts has launched laser material processing as a leading tool in the production of highly responsible machines. Laser drilling and laser shock peening are laser techniques that promise high quality treated parts.

Achieving optimal hole quality is an important area of current research, and laser drilling has several advantages over conventional procedures. Also, conventional laser surface treatments are mostly thermal or thermo-chemical while laser shock peening induces shock waves of purely mechanical or thermomechanical effects [1].

Parametric optimisation of industrial processes has been mainly performed using statistical methods, such

Author's address: Tatjana Šibalija, Belgrade Metropolitan University, Faculty of Information Technology; Faculty of Management; Belgrade, Tadeuša Košćuška 63

e-mail: tsibalija@gmail.com

Paper received: 17.3.2021.

Paper accepted: 25.03.2021. as response surface methodology (RSM) and Taguchi's robust parameter design. Although RSM can simultaneously consider multiple responses, it does not address correlations among responses and does not directly take into account the response variability.

The Taguchi method adequately addresses both response mean and variation, but it has been designed for a single-response problem. Several statistical approaches have been developed to apply the Taguchi method for multiple responses.

But, they are not suitable for global optimization, since they consider only discrete process parameter values used in experimental trials. Detail discussion on the parametric optimization approaches could be found in [2].

The metaheuristic search techniques present a plausible alternative since they search throughout a continual space of solutions toward a global optimum. A recent study indicated that GA, SA and PSO have been the most frequently applied metaheuristics in optimizing manufacturing processes [3]. Therefore, these three algorithms are implemented within the proposed methodology to locate a global solution (optimal process parameters setting) for two laserbased processes. Details of GA could be found in [4], of SA in [5], and details of PSO in [6]. 


\section{OPTIMIZATION METHODOLOGY}

The experiments are conducted to collect the process data: process control parameters are varied and the output characteristics are measured for each experimental trial. Outputs are expressed by Taguchi's quality loss function (QL), to adequately represent a relative financial significance of each output for the product user. The QLs are calculated based on the signal-to-noise ratio (SNR), utilizing common formulas defined by G. Taguchi [7] depending on the type of requirements for the output (smaller-the-better - STB; larger-the better - LTB; nominal-the-best - NTB). The process outputs are correlated, so it is necessary to uncorrelated them for a further analysis. The normalized $\mathrm{QL}$ values $\left(\mathrm{NQL}_{\mathrm{i}}(\mathrm{k}) \in[0,1], i\right.$ is number of the output characteristic, $k$ is number of the experimental trial) are fed into principal component analysis (PCA) to obtain independent components (PCs) with scores:

$$
Y_{j}(k)=\sum_{i=1}^{p} N Q L_{i}(k) \cdot V_{i j}
$$

where $j$ is the PC number and $V_{i j}$ are elements of the corresponding eigenvector. The PCA shows the percentages of contribution $\left(\omega_{j}, j=1, \ldots p\right)$ of each PC in the total variation. The PCA details could be found in [8]. Aiming to integrate independent PCs into a single measure, grey relational analysis (GRA) is applied. First, $Y j(k)$ are transformed into set of comparable sequences, and then grey relational coefficient $\varepsilon_{j}$ is calculated. The grey relational grade is computed and adopted as a single process measure $\left(\mathrm{SPM}_{\mathrm{k}}=\gamma_{\mathrm{k}} \in[0\right.$, 1]):

$$
S P M_{k}=\gamma_{k}=\sum_{j=1}^{P} w_{j} \varepsilon_{j}(k)
$$

Therefore, a single process measure (SPM) is obtained in a totally objective manner. The higher SPM, the better is the process. The GRA details could be found in [9]. Finally, effects of the process parameters on SPM are computed as the mean of all SPM values for each parameter level. The potentially good solution (from a space of discrete solutions) is obtained by selecting the levels with the maximal effect on SMP. This solution serves to initialize the population or point in metaheuristic algorithms. The details could be found in [2].

When the analytical process model is unknown, artificial neural networks (ANNs) are utilized to define relationship between process parameters (input layer) and SPM (output layer). The feed forwarded backpropagation ANN with one hidden layer is used, with the tangent sigmoid and linear functions, for hidden and output neurones, respectively. A smaller learning rate $(0.01)$ and a larger momentum factor (0.9) are selected to ensure an appropriate training. Different topologies (number of neurones in the hidden layer) are developed in Matlab. The network with minimal mean square error (MSE) between the original data fed into network and actual network predictions is selected as the process model. In addition, it has to have a high correlation between the original data and network predictions (coefficient of correlation $\mathrm{R}$ higher than $0.95)$.

The process model presents an objective function for three metaheuristics whose performances are compared: GA, SA and PSO. Since previous studies indicated that the algorithm's outputs are highly dependent on its own tuning, major hyper-parameters of all three algorithms are varied to assess their effect on the obtained solution. The GAs are implemented using the following hyper-parameters: population size $=5 n$ ( $n$ is the number of process parameters); initial population defined in proximity of a potentially good solution (the result of the statistical part of the proposed methodology); rank scaling function; forward migration with the fraction of 0.2 ; adaptive feasible mutation; three types of selection function were tested: stochastic uniform, roulette wheel and tournament; three types of crossover were tested: single point, two points and arithmetic. Therefore, nine GAs are developed for each optimisation problem. The SA algorithms are developed with the following tunings: initial point seeded with a potentially good solution; initial temperature: 10, 100 and 500; reannealing interval: 10 and 100; temperature function: exponential, fast, and Boltzmann; annealing functions: fast and Boltzmann, giving in total 36 SA algorithms. The PSO is implemented considering two options: randomly generated initial swarm, and initial swarm seeded with a potentially good solution. For each of these options, 30 algorithms are run with the following settings: swarm size: $2 n, 5 n$ and $12 n$; inertia weight range: [0.1; 1.1$],[0.4 ; 0.9]$, $[0.5 ; 2.5],\left[1.0 ;\right.$; 5.0]; learning factors: $\mathrm{c}_{1}=\mathrm{c}_{2}=0.1$; $\mathrm{c}_{1}=\mathrm{c}_{2}=0.5 ; \mathrm{c}_{1}=\mathrm{c}_{2}=2.0 ; \mathrm{c}_{1}=\mathrm{c}_{2}=5$, and $\mathrm{c}_{1}=0.7, \mathrm{c}_{2}=1.5$. All three metaheuristics were implemented in Matlab environment, and run for 5000 iterations. The results of three algorithms are benchmarked in respect to the quality of obtained solution (maximal SPM value is preferable), sensitivity to the algorithm's hyperparameters tuning (lower sensitivity is favourable, i.e. lower dispersion of the algorithms' results obtained with different tunings), and convergence rate (number of iterations needed to achieve a global optimum).

\section{PARAMETRIC OPTIMIZATION OF LASER- BASED PROCESSES}

\subsection{Laser drilling: parametric optimization and validation}

The experiment was performed to find the optimal values of process parameters (pulse frequency $-f$ varied on three levels: 5,7 and $9 \mathrm{~Hz}$, and pulse duration 
$-t$ varied on five levels: $0.5,0.7,1.0,1.2,1.8 \mathrm{~ms}$ ) that meets requirements for seven outputs: entry-side hole diameter (Dent, target $=420 \mu \mathrm{m}$, NTB type), exit-side hole diameter (Dex), circularity of entry-side hole (Cen), circularity of exit-side hole (Cex), Aspect ratio (AR), taper $(\theta)$ and spatter (Sa) .For Dex, Cen, Cex and AR the objective is to reach maximal value (LTB type), and for responses $\theta$ and $\mathrm{Sa}$ are required to be minimized (STB type). The experimental details could be found in [10].

Using the data from Table 1 (control parameters and SPM values for 15 trials), BP ANNs were developed with different topologies. The network 215-1 showed minimal error and maximal coefficient of correlation (MSE $=1.310^{-6} ; \mathrm{R}=0.98$ ), and, therefore, was adopted as a neural process model [10]. It presented the objective function for three metaheuristics: their results are given in Table 2 (the second and third raws show results obtained from all tested algorithms; the forth and fifth raws show the global optimum data; the sixth raw shows the number of iterations needs to converge to a solution, while the last raw shows the number of iterations needs to locate the global solution).

Table 1. Experimental results and calculated SPM for laser drilling study

\begin{tabular}{|c|c|c|c|c|c|c|c|c|c|c|}
\hline \multirow{2}{*}{ No. } & \multicolumn{2}{|c|}{ Control parameters } & \multicolumn{7}{|c|}{ Output characteristics } & \multirow{2}{*}{$\begin{array}{l}\mathrm{SPM}_{\mathrm{k}} \\
\mathrm{k}=1, . .15\end{array}$} \\
\hline & $\mathrm{f}$ & $\mathrm{t}$ & Dent & Dex & Cen & Cex & AR & $\theta$ & $\mathrm{Sa}$ & \\
\hline 1 & 5 & 1.8 & 432.7 & 255.3 & 0.94 & 0.88 & 2.77 & 7.22 & 0.027 & 0.5609 \\
\hline 2 & 5 & 1.2 & 427.9 & 248.8 & 0.94 & 0.87 & 2.80 & 7.29 & 0.023 & 0.5136 \\
\hline 3 & 5 & 1.0 & 422.4 & 241.4 & 0.94 & 0.89 & 2.84 & 7.37 & 0.023 & 0.5176 \\
\hline 4 & 5 & 0.7 & 415.6 & 232.3 & 0.97 & 0.91 & 2.89 & 7.46 & 0.018 & 0.5271 \\
\hline 5 & 5 & 0.5 & 410.6 & 226.1 & 0.98 & 0.93 & 2.92 & 7.51 & 0.017 & 0.5514 \\
\hline 6 & 7 & 1.8 & 426.3 & 250.1 & 0.93 & 0.88 & 2.82 & 7.18 & 0.044 & 0.5409 \\
\hline$\ldots$ & & & & & & & & & & \\
\hline 15 & 9 & 0.5 & 394.1 & 215.7 & 0.94 & 0.95 & 3.05 & 7.26 & 0.064 & 0.6125 \\
\hline
\end{tabular}

Table 2. Results of three algorithms in optimizing laser drilling parameters

\begin{tabular}{|l|l|l|l|l|}
\hline Results & GA & SA & $\begin{array}{l}\text { PSO with random } \\
\text { initialization }\end{array}$ & $\begin{array}{l}\text { PSO with good } \\
\text { initialization }\end{array}$ \\
\hline SPM range & $0.7133 \div 0.7523$ & $0.7508 \div 0.7523$ & $0.7521 \div 0.7523$ & $0.7510 \div 0.7523$ \\
\hline Optimal parameters range & $\begin{array}{l}{[7.000 \div 7.498 ;} \\
0.500 \div 0.503]\end{array}$ & $\begin{array}{l}{[7.430 \div 7.568 ;} \\
0.500 \div 0.502]\end{array}$ & $\begin{array}{l}{[7.496 \div 7.514 ;} \\
0.500]\end{array}$ & $\begin{array}{l}{[7.442 \div 7.508 ;} \\
0.500]\end{array}$ \\
\hline Max.SPM (global optimum) & 0.7523 & 0.7523 & 0.7523 & 0.7523 \\
\hline Optimal parameters (global) & {$[7.5 ; 0.5]$} & {$[7.5 ; 0.5]$} & {$[7.5 ; 0.5]$} & {$[7.5 ; 0.5]$} \\
\hline $\begin{array}{l}\text { Number of iterations to find } \\
\text { solution }\end{array}$ & $1 \div 1995$ & $5 \div 450$ & $3 \div 55$ & $2 \div 85$ \\
\hline $\begin{array}{l}\text { Number of iterations to find global } \\
\text { optimum }\end{array}$ & 4 & 5 & 6 & 9 \\
\hline
\end{tabular}

From nine GAs with different settings, only two algorithms found to the global optimum (max. SPM value of 0.7523 ), converging to the global solution in fourth and fifth iterations, respectively. Their hyperparameters were set as follows: selection function: stochastic uniform and roulette wheel; crossover function: two points. The remaining seven GAs found inferior solutions. Therefore, a high effect of the main GA hyper-parameters on the quality of the solution is clearly demonstrated. From 36 SA algorithms, majority (more than half) found the global optimum and the fastest algorithm converged in the fifth iteration. The SA algorithms that found the global optimum were tuned as follows: initial temperature: 100 and 500; annealing function: Boltzmann and fast; temperature function: exponential and fast; reannealing interval: 10 and 100. Since the range of SPM values obtained by $\mathrm{SA}$ is significantly narrower than for GA, it is clear that the effect of SA parameters on the solution quality is lower than for GA. Both GA and SA were initialized by a potentially good solution $(\mathrm{f}=7.0 ; \mathrm{t}=0.5)$. For PSO algorithms, two main options were tested. Results of PSO algorithms with random initialization showed that only one algorithm found sub-optimal solution (swarm size $=2 n=4$; inertia weight range $=[0.1 ; 1.1]$, learning factors $\mathrm{c}_{1}=\mathrm{c}_{2}=5$ ). The remaining 29 algorithms converged to the global optimum; the fastest one converged in the sixth iteration (swarm size $=12 n=24$; 
inertia weight range $=[1.0 ; 5.0]$, learning factors $\mathrm{c}_{1}=\mathrm{c}_{2}=0.5$ ). In total 28 PSOs with potentially good initialization found the global optimum; the fastest one converged in the ninth iteration ( swarm size $=12 n=24$; inertia weight range $=[0.1 ; 1.1]$, learning factors $\mathrm{c}_{1}=\mathrm{c}_{2}=0.5$ ). The two algorithms that found sub-optimal solutions were set se as follows: swarm size $=2 n=4$ and $5 n=10$; inertia weight range $=[0.1 ; 1.1]$, learning factors $c_{1}=c_{2}=5$. From Table 2 it is visible that the range of SPM values obtained by PSO is narrower than for SA, hence demonstrating a favorable robustness of PSO algorithm in respect to its own settings. PSO algorithms with random initialization showed marginally better robustness and convergence rate than PSO algorithms with good initialization. Therefore, the state of initial swarm does not significantly affect the quality of solution.

To conclude, PSO algorithm demonstrated the best effectiveness (solution quality) and insensitivity to its own tuning, followed by SA that showed significantly better results than GA. All three algorithms showed similar rate of convergence to the global optimum.

The adopted optimal solution $(\mathrm{f}=7.5 \mathrm{~Hz} ; \mathrm{t}=0.5 \mathrm{~ms})$ was verified in a confirmation run. It could be seen that the hole drilled using optimal process parameters shows better geometrical characteristics than the hole drilled using initial process parameter values. The optimized drilling parameters provided the best circularity, i.e. the circularity nearest 1 , the second best aspect ratio and taper compared to the holes drilled by non optimized laser processing parameters. The metallurgic characteristic such as spatter area was the smallest when the material was drilled by optimized parameters.

\subsection{Laser shock peening: parametric optimization and validation}

The experiment was conducted to locate the optimal values of process parameters (voltage $-V$ varied on three levels: 200, 234 and $250 \mathrm{~J}$, focus position $-f$ varied on three levels: 1,2 and 3 , and pulse duration $-t$ varied on three levels: $0.6,0.7$ and $0.8 \mathrm{~ms}$ ) that satisfy requirements for seven outputs: circularity $(\mathrm{C})$, grain size (GS), roughness (Ra), average maximum roughness valley depth (VD), average maximum roughness peak height $(\mathrm{PH})$, skewness $(\mathrm{S})$ and kurtosis (K). The first response aimed to be maximized (LTB) and the remaining ones should be minimized (STB). Details could be seen in [11].

The set of ANNs was trained to establish the relationship between process parameters and SPM, using data from Table 3 . The betwork with 16 hiden neurones, i.e. ANN 3-16-1, showed the best performance (MSE $\left.=4.210^{-5} ; \mathrm{R}=1.00\right)$ and was endorsed as LSP model [11], presenting an input for metaheuristics.
Results of implementation of three algorithms in optimizing LSP parameters are listed in Table 4.

The GA and SA algorithms with different setting found only local optima. From nine GAs, four GAs found the maximal SPM value of 0.9305 (their settings were: selection function: stochastic uniform and roulette wheel; crossover function: single point and arithmetic), but they did not reach the global optimum. All SA algorithms found the same SPM value of 0.9305; the fastest one converged to a final solution in the fifth iterations (with settings: initial temperature: 100; annealing function: Boltzmann; temperature function: Boltzman; reannealing interval: 10). The SA algorithm showed slightly lower dispersion of results obtained by different settings than GA. The SA demonstrated significantly faster convergence than GA, which is surprising since GA performs populationbased search contrary to SA that perform point-topoint search throughout the space. For GA and SA algorithms, initial solution was seeded with a potentially good solution $(\mathrm{V}=200 ; \mathrm{Fp}=3 ; \mathrm{t}=0.8)$. The PSO algorithms found significantly better solution, obtaining the global optimum (SPM $=0.9835$, optimal process parameters: $\mathrm{V}=216.55 \mathrm{~J} ; \mathrm{Fp}=4 ; \mathrm{t}=0.9 \mathrm{~ms}$ ) that was adopted as the problem solution. All tested PSO algorithms, both with random and potentially good initialization, located the global optimum. The fastest PSO with random initial swarm converged in the third iterations (swarm size $=12 n=36$; inertia weight range $=$ $[1.0 ; 5.0]$, learning factors $\mathrm{c}_{1}=\mathrm{c}_{2}=2$ ). The fastest PSO with a good initial swarm converged in the fourth iteration (swarm size $=12 n=36$; inertia weight range $=$ $[0.4 ; 0.9]$, learning factors $\mathrm{c}_{1}=\mathrm{c}_{2}=2$ ).

Therefore, PSO demonstrated significantly better effectiveness in this study, especially in terms of the solution quality, since GA and PSO did not manage to find the global optimum. Besides, PSO showed remarkable robustness in respect to its hyper-parameter values. There are no significant differences between PSO algorithms with random and potentially good initialization. Moreover, PSO convergence rate was good, higher than SA and significantly higher than GA.

The validation run was performed to verify the results obtained by using the endorsed optimal solution $(\mathrm{V}=2216.55 \mathrm{~J} ; \mathrm{Fp}=4 ; \mathrm{t}=0.9 \mathrm{~ms})$. The optimized LSP improved the surface quality and microhardness and caused favorable microstructure transformations, which theoretically indicates possible improvements in mechanical properties and fatigue strength. The optimized parameters provided the smallest roughness characteristics, and the highest microhardness compared to the characteristics obtained by nonoptimized processing parameters. The circularity was close to 1 , which is the second-best result of all spots obtained by non-optimized parameters in this experiment. 
Table 3. Experimental results and calculated SPM for LSP study

\begin{tabular}{|c|c|c|c|c|c|c|c|c|c|c|c|}
\hline \multirow{2}{*}{ No. } & \multicolumn{3}{|c|}{ Process parameters } & \multicolumn{7}{|c|}{ Output characteristics } & \multirow{2}{*}{$\begin{array}{l}\mathrm{SPM}_{\mathrm{k}} \\
\mathrm{k}=1, \ldots 9\end{array}$} \\
\hline & $\mathrm{V}$ & $\mathrm{f}$ & $\mathrm{t}$ & C & GS & $\mathrm{Ra}$ & VD & $\mathrm{PH}$ & S & $\mathrm{K}$ & \\
\hline 1 & 200 & 1 & 0.6 & 0.91 & 268.4 & 320.3 & 822.3 & 716.0 & 0.14 & 3.44 & 0.8105 \\
\hline 2 & 200 & 2 & 0.7 & 0.93 & 325.3 & 295.7 & 771.3 & 758.7 & 0.08 & 3.92 & 0.7859 \\
\hline 3 & 200 & 3 & 0.8 & 0.96 & 366.9 & 288.7 & 762.0 & 781.3 & 0.16 & 3.66 & 0.8153 \\
\hline 4 & 234 & 1 & 0.7 & 0.95 & 377.6 & 409.3 & 1148.7 & 1033.7 & -0.09 & 3.36 & 0.4755 \\
\hline \multicolumn{12}{|l|}{$\ldots$} \\
\hline 9 & 250 & 3 & 0.7 & 0.87 & 345.4 & 328.7 & 873.7 & 940.0 & 0.17 & 3.56 & 0.6482 \\
\hline
\end{tabular}

Table 4. Results of three algorithms in optimizing LSP parameters

\begin{tabular}{|l|l|l|l|l|}
\hline Results & GA & SA & $\begin{array}{l}\text { PSO with random } \\
\text { initialization }\end{array}$ & $\begin{array}{l}\text { PSO with good } \\
\text { initialization }\end{array}$ \\
\hline SPM range & $0.9304 \div 0.9305$ & 0.9305 & 0.9835 & 0.9835 \\
\hline Optimal parameters range & $\begin{array}{l}{[200 \div 201.5 ; 3.98 \div} \\
4.0 ; 0.88 \div 0.90]\end{array}$ & $\begin{array}{l}{[200 \div 200.5 ; 3.99 \div} \\
4.0 ; 0.89 \div 0.90]\end{array}$ & {$[216.55 ; 4 ; 0.9]$} & {$[216.55 ; 4 ; 0.9]$} \\
\hline Max.SPM (global optimum) & 0.9305 & 0.9305 & 0.9835 & 0.9835 \\
\hline Optimal parameters (global) & {$[200 ; 4 ; 0.9]$} & {$[200 ; 4 ; 0.9]$} & {$[216.55 ; 4 ; 0.9]$} & {$[216.55 ; 4 ; 0.9]$} \\
\hline $\begin{array}{l}\text { Number of iterations to find } \\
\text { solution }\end{array}$ & $580 \div 1625$ & $5 \div 260$ & $3 \div 80$ & $4 \div 78$ \\
\hline $\begin{array}{l}\text { Number of iterations to find global } \\
\text { optimum }\end{array}$ & 580 & 5 & 3 & 4 \\
\hline
\end{tabular}

\section{DISCUSSION}

The results of application of three major metaheuristics on the above two case studies showed a favourable performance of PSO, followed by SA that showed overall better results than GA. PSO located a global optimum in both studies, showing a high quality of the obtained solutions. It also showed a very good robustness in respect to its own parameters and very fast convergence.

Therefore, the PSO algorithm can be suggested for future reference in terms of addressing process optimization problems. Regarding the PSO settings, it was demonstrated that the state of initial does not affect the solution quality, which is in accordance to the previous findings [12]. The PSO hyper-parameters that indicated beneficial performance in two studies are: larger swarm size $(>5 n)$; inertia weight range $=$ $[0.1 ; 1.1],[1.0 ; 5.0]$ and $[0.4 ; 0.9]$, learning factors $\mathrm{c}_{1}=\mathrm{c}_{2}=2, \mathrm{c}_{1}=\mathrm{c}_{2}=0.5$, which is mainly in accordance to the previous study results [12].

The smaller swarm size (e.g. 2n), and learning factors $c_{1}=c_{2}=5$ showed inferior results in these two studies. The SA algorithm performed better than GA in the observed studies, especially in terms of the solution quality and lower sensibility to its own tuning. However, it has to be noted that SA failed to converge to a global optimum in one study. The SA settings that indicated the best performance in two studies are: (i) high initial temperature (e.g. 100, 500); (ii) annealing function: Boltzmann and fast; (iii) temperature function: exponential and fast; (iv) reannealing interval: 10 and 100 .

The genetic algorithm showed inferior performance in two studies: its results are highly dependent on its own settings; it frequently failed to locate a global optimum; its convergence rate was surprisingly low, even lower than SA that is not population-based metaheuristics. Anyhow, the stochastic uniform and roulette wheel selection function gave better results than tournament selection in both studies, in accordance to previous findings [2]. Since such unbeneficial results were achieved with the population size of $5 \mathrm{n}$, it could be recommended to work with populations larger than $5 \mathrm{n}$.

Verification runs for both laser processing confirmed the process of optimization. The hole obtained by optimal processing parameters has the best quality. The hole has a circularity very near zero which makes this process of optimization to be a great candidate for hole drilling in the aero and space industry.

The surface obtained by optimized parameters in laser shock peening of material shows the best surface and mechanical characteristics comparing to the surface characteristics obtained by non-optimized parameters. 


\section{CONCLUSION}

The two heterogeneous laser-based processes have been successfully optimized using the proposed methodology, which was verified in a practice. The effectiveness of three metaheuristic algorithms have been assessed, demonstrating a superior performance of PSO algorithm; SA algorithm showed, in overall, better results than GA. The guidelines for the algorithms' own settings are presented.

Application of the teaching-learning based optimization (TLBO) algorithm is in progress, and future activities will include application of other recent metaheuristics (e.g. Jaya algorithm) in optimizing laser-based processes. The future activities will also include optimization of other novel laser-based processes, such as laser cutting, laser shock peening by femtosecond and picosecond lasers and laser shock peening of additive manufactured material.

\section{REFERENCES}

[1] Petronic S, Milovanovic D, Milosavljevic A, .Radovanovic Z, Eric-Cekic O, Jovicic R, Laser treatments of Nimonic 263 alloy, Journal Materials Protection, Vol. 60, No. 1, pp. 26 - 43, 2019. ISSN 0351-9465, E-ISSN 2466-2585, UDC:620.197.5:669.018.1, doi:$10.5937 /$ zasmat1901026P (in Serbian)

[2] Sibalija T, Majstorovic V, Advanced Multiresponse Process Optimisation, Springer: Berlin, Germany, 2016.

[3] Sibalija T, Particle Swarm Optimisation in Designing Parameters of Manufacturing Processes: A Review (2008-2018). Applied Soft Computing 84: 105743 , DOI: 10.1016/j.asoc.2019.105743, 2019
[4] Sivanandam S. N, Deepa S. N, Introduction to Genetic Algorithms, Springer-Verlag Berlin, Heidelberg, 2019.

[5] Spall J, Introduction to stochastic search and optimisation. John Wiley \& Sons, Inc. New Jersey, 2003.

[6] Kennedy J, Eberhart R, Particle swarm optimization. In Proceedings of ICNN'95-International Conference on Neural Networks, Perth, Australia, 27 Nov 1 Dec. 1995.

[7] Taguchi G, Chowdhury S, Wu Y, Taguchi's quality engineering handbook, Michigan: Wiley, 2005.

[8] Jackson J E, A user's guide to principal components, New York: Wiley, 1991.

[9] Lu M, Wevers K, Grey System Theory and Applications: A Way Forward. Journal of Grey System Vol. 10, No.1, pp. 47-54, 2007.

[10]Sibalija T, Petronic S, Majstorovic V, Prokic-Cvetkovic R, Milosavljevic A, Multi-response design of $\mathrm{Nd}$ :YAG laser drilling of Ni-based superalloy sheets using Taguchi's quality loss function, multivariate statistical methods and artificial intelligence. Int. J. Adv. Manuf. Technol. Vol. 54, pp. 537-552, 2011.

[11]Sibalija T, Petronic S, Majstorovic V, Milosavljevic A, Modelling and optimisation of laser shock peening using an integrated simulated annealing-based method. Int. J. Adv. Manuf. Technol. Vol. 73, pp. 11411158, DOI: 10.1007/s00170-014-5917-1, 2014.

[12] Sibalija T, Petronic, S, Milovanovic, D, Experimental optimization of Nimonic 263 laser cutting using a particle swarm approach. Metals Vol. 9, No. 11, pp. 114-130, 2019.

\section{REZIME}

\section{POREĐENJE METAHEURISTIČKIH ALGORITAMA PRI PARAMETARSKOJ OPTIMIZACIJI PROCESA LASERSKE OBRADE}

Rad prikazuje parametarsku optimizaciju dva heterogena procesa laserske obrade materijala sa više izlaznih karakteristika (lasersko bušenje i deformaciono ojačavanje laserom). koristeći naprednu optimizacionu metodologiju. Podaci dobijeni eksperimentom se obrađuju statističkim metodama kako bi se uzeli u obzir zahtevi za više izlaznih karakteristika. nakon čega se proces modeluje koristeći veštačke neuronske mreže. Neuronski model procesa predstavlja funkciju cilja za tri metaheuristička algoritma čije efektivnosti se porede: algoritam optimizacije rojem čestica, algoritam simuliranog odgrevanja $i$ genetski algoritam. Rezultati su analizirani u smislu kvaliteta dobijenih rešenja i brzine konvergencije. kao i u smislu uticaja sopstvenih parametara algoritama na postignuta rešenja. Usvojeni optimizacioni rezultati su uspešno verifikovani u praksi. Prikazane su preporuke za izbor metaheurističkog algoritma i smernice za podešavanje algoritama.

Ključne reči: algoritam optimizacije rojem čestica; algoritam simuliranog odgrevanja; genetski algoritam; parametarska optimizacija; bušenje laserom; deformaciono ojačavanje laserom 